\title{
Advancing the New Communications Framework for HIV/AIDS: The Communicative Constitution of HIV/AIDS Networks in Tanzania's HIV/AIDS NGO Sector
}

\author{
James O. Olufowote ${ }^{1}$, Johnson S. Aranda ${ }^{1}$, Guoyu E. Wang ${ }^{1}$, Danni Liao ${ }^{1}$ \\ ${ }^{1}$ The University of Oklahoma, USA \\ Correspondence: James O. Olufowote, The University of Oklahoma, USA. \\ Received: March 14, 2017 \\ doi:10.11114/smc.v5i1.2390 \\ Accepted: April 25, 2017 \\ Online Published: April 26, 2017 \\ URL: https://doi.org/10.11114/smc.v5i1.2390
}

\begin{abstract}
Although health communication research on HIV/AIDS has acknowledged the work of HIV/AIDS non-governmental organizations (NGOs), we know little about how such NGOs are collaborating in their response to the epidemic in sub-Saharan Africa (SSA). UNAIDS estimated that over two-thirds of world-wide HIV infections and AIDS-related deaths take place in SSA and normative models have highlighted organizational collaborations as an important part of the response to public health risks and crises. This study advanced the New Communications Framework for HIV/AIDS by drawing on a constitutive model of communication to develop a discursive perspective on HIV/AIDS NGO collaborations. Analyses of interviews with 36 leaders of Tanzanian HIV/AIDS NGOs resulted in (a) networks of organizations of people living with HIV/AIDS (PLWHA) and (b) networks expressing the following identities: as single entities that unify PLWHA organizations in/across administrative divisions, as structures for reaching grassroots PLWHA and facilitating their participation in decision-making forums at various scales, and as vehicles for various social impacts such as advocacy for PLWHA.
\end{abstract}

Keywords: HIV/AIDS, non-governmental organizations, organizational identity, organizational networks

\section{Introduction}

Health communication studies of HIV/AIDS have highlighted the important roles of public health organizations (Airhihenbuwa, Makinwa, \& Obregon, 2000). Although hospitals emphasize curing and treatment, public health organizations originate from different sectors of society (e.g., for-profit, government, and non-profit) and instead emphasize advocacy and education (Zoller, 2010). Those from the non-profit sector are often engaged in community organizing defined by Dearing (2003) as "community empowerment through grassroots initiation and activity" (p. 208) that stimulates members to "improve certain conditions experienced in a community" (p. 208).

Community-based non-profits with a focus on HIV/AIDS are constituted by staff and volunteers from local communities that are affected or infected (DeJong \& Mortagy, 2013). These organizations are locally-owned, they operate at the grassroots (Cooper \& Shumate, 2012), and they provide services such as care and support for marginalized, poor, and vulnerable populations (e.g., Kiley \& Hovorka, 2006; Svenkerud \& Singhal, 1998).

The New Communications Framework for HIV/AIDS (NCF) is a resource for HIV/AIDS prevention in sub-Saharan Africa that draws attention to HIV/AIDS non-governmental organizations (NGOs) (Airhihenbuwa et al., 2000; Diop, 2000). In response to concerns about the ability of individual-level health communication models/theories to stem the tide of the epidemic in Africa, Asia, the Caribbean, and Latin America (see Airhihenbuwa \& Obregon, 2000), Airhihenbuwa et al. (2000) argued for a shift in emphasis from individual behaviors to ecological contexts ${ }^{1}$. In one context, they highlighted HIV/AIDS NGO collaborations.

Despite drawing attention to NGO collaborations, the NCF did not provide a discursive perspective on these

\footnotetext{
${ }^{1}$ Airhihenbuwa et al. (2000) pointed to the five ecological contexts of critical issues facilitated by governments, culture, gender relations, socio-economic status, and spirituality. These ecological contexts resonate with the broader cultural, national, and historical-level concerns that Craig (1999) associated with the critical and socio-cultural traditions of communication theory.
} 
collaborations. This study developed a discursive model of collaboration and drew on it to study HIV/AIDS NGO collaborations in Tanzania. Tanzania is an east-African nation that has a 5.3\% adult HIV/AIDS prevalence rate that is ranked $12^{\text {th }}$ highest in the world ("United Nations Programme on HIV/AIDS," 2015). Through interviews with 36 leaders of 34 local HIV/AIDS NGOs in Tanzania, the study provides insight into the communicative constitution of people living with HIV/AIDS (PLWHA) organizational networks in the HIV/AIDS NGO sector. In the sections that follow, the NCF is presented, it is used to organize the literature on HIV/AIDS NGOs, and a discursive perspective on NGO collaborations is provided through a constitutive model of communication.

\section{The New Communications Framework for HIV/AIDS}

The NCF introduced the ecological contexts of government and policy, culture, socio-economic status (SES), gender, and spirituality. The context of government and policy pointed to supportive climates for collaborations by NGOs and regional organizations. The culture context highlighted the ideology of culture as a generator of health (and not only a barrier) and cultural differences such as collectivism. The SES context introduced the considerations of affordability, allocation, and distribution of health resources. The gender context pointed to the conditions and practices that make women vulnerable to HIV and advocated for gender equity and the foregrounding of gender in HIV programs. The spirituality context emphasized the link between spirituality and health and pointed to the importance of religious leaders and traditional healers (Airhihenbuwa et al., 2000). Health communication research on HIV/AIDS has taken up some of these considerations (e.g., Bekalu \& Eggermont, 2014; Uwah, 2014). For example, studies have considered cultural contexts (e.g., Basu \& Dutta, 2009), economic contexts (e.g., Dasgupta, 2013), gender relations (Dako-Gyeke, 2013), and spirituality (e.g., Muturi, 2011).

The NCF's context of government and policy highlighted collaboration by community organizations, NGOs, and regional organizations. In a supplement of the Journal of Health Communication, Airhihenbuwa et al. (2000) considered HIV/AIDS NGO collaborations at different scales (i.e., local, regional, global) when they wrote "An important role of government is fostering interregional and intraregional collaboration in HIV/AIDS programs such as sharing lessons learned within and between regions and facilitating cross-border interventions" (p. 105). The supplement also provided the successes of Senegal, Thailand, and Uganda (Airhihenbuwa et al., 2000; Diop, 2000). For example, Diop (2000) attributed Uganda's success to "formation of networks of organizations that help with coping mechanisms for the disease" (p. 117).

Several studies have taken up the NCF's focus on global South HIV/AIDS NGOs' collaborations at different scales. Studies have emphasized collaborations taking place in the same global South nation (de Souza, 2009; Garcia \& Parker, 2011; Kiwanuka-Tondo, Albada, Waters, Jameson, \& Hamilton, 2011). For example, Kiley and Hovorka (2006) studied HIV/AIDS NGOs in Botswanna. They found the NGOs marginalized, suffering from challenges to collaboration (e.g., travel distance), lacking resources, being over- or under-represented relative to populations, and lacking attention to socio-cultural issues such as stigma and gender.

A few studies have pointed to global South HIV/AIDS NGOs' regional collaborations (e.g., Cooper \& Shumate, 2012). An example comes from Murray, Garcia, Munoz-Laboy, and Parker (2011) who sought to understand a partnership between the Catholic Church and the Brazilian Ministry of Health. They found that a series of meetings, starting in 1999, led to the creation of the AIDS Pastoral, a regional Latin-American network for HIV/AIDS care and prevention that combined both biomedical and spiritual approaches.

Several studies have also examined global South HIV/AIDS NGOs' global collaborations (e.g., Desouza \& Dutta, 2008; Murphy, 2013; Shumate \& Dewitt, 2008). For instance, drawing on an historical study of relationships among Tanzania's faith-based health sector, Tanzania's government, and global north international non-governmental organizations (INGOs), Jennings (2015) argued that Tanzania inherited from the colonial era a vulnerable and insufficiently-funded health system (based on partnerships between the government and the faith-based health sector). To fund services, this health sector partnered with global North INGOs, which, according to Jennings, exacerbated the functioning of the health system because it undermined accountability to Tanzanians.

As a resource for HIV/AIDS prevention in sub-Saharan Africa, the NCF highlighted HIV/AIDS NGO collaborations at different scales. To develop a discursive perspective on these collaborations, the study next turns to the organizational communication literature.

\subsection{Inter-Organizational Collaboration}

Inter-organizational collaboration (IOC) is defined as "(1) cooperation, coordination, and exchange of resources (e.g., people, funding, information, ideas), and (2) mutual respect for individual and/or joint goals" (Lewis, Isbell, \& Koschmann, 2010, p. 462). 


\subsubsection{IOC Collaborative Arrangements}

IOC can be classified as a social collective or an informal process (Guo \& Acar, 2005; Kwait, Valente, \& Celentano, 2001). IOC as a social collective refers to a single entity with close-knit administrative or systems-level relationships that are often long-term and involve administrative commitments that decrease the autonomy of individual organizations. An example is the Canadian Treatment Advocate Council (CTAC), which included pharmaceutical companies, organizations of PLWHA, and HIV/AIDS service organizations (Hardy, Lawrence, \& Phillips, 2006). IOC-as-social-collective includes forms such as alliances, consortia, and networks.

IOC as informal process, on the other hand, can be defined as service-oriented, loose-knit, and temporary. It minimally impacts each organization's autonomy and includes processes such as client referrals and the reciprocal exchange of informational and/or material resources (e.g., Werber, Derose, Dominguez, \& Mata, 2012). For example, in a study of collaboration among 30 HIV/AIDS service agencies in Baltimore, Maryland, Kwait et al. (2001) found informal IOC processes such as information exchange and client referrals having greater densities than the collective IOC forms of written agreements and joint-program linkages.

Different benefits accrue to the collaborative arrangements. Social collectives are associated with multiple-party benefits (Lees, Kielmann, Cataldo, \& Gitau-Mburu, 2012), political influence (Hardy et al., 2006), and obtaining funding from third parties (Kwait et al., 2001; Takahashi \& Smutny, 2001). Informal IOC is associated with swift responses to clients (Kwait et al., 2001) and the mutual exchange of resources (Werber et al., 2012).

This study focused on IOC-as-social-collectives. Stated differently, the study focused on the collaborative forms that involve HIV/AIDS NGOs. In developing a discursive perspective on these forms, the study next reviews three different research traditions of IOC.

\subsubsection{IOC Research Traditions}

Three traditions in organizational communication are the network, critical, and discourse traditions. Studies from the network tradition draw primarily on surveys and network analysis to test the collaborative linkages in a field of organizations for particular forms and patterns (e.g., Khosla, Marsteller, Hsu, \& Elliott, 2016; Shumate, Fulk, \& Monge, 2005; M. Taylor \& Doerfel, 2003). For example, Atouba and Shumate (2010) drew on network analysis to explain the network structure and networking predictors among 108 international organizations. They found several factors explaining the likelihood of collaboration (e.g., reciprocal ties, similarity in type of organization, similarity in funding sources).

Studies from the critical tradition, sensitive to power relations among organizations and communities, draw on methods such as ethnographies and case studies to interrogate processes and consequences of collaborating such as (a) (dis)empowering marginalized communities and/or (b) achieving and/or undermining democratic ideals among collaborators (e.g., Contu \& Girei, 2014; Dempsey, 2010; Norander \& Harter, 2012). For example, Murphy's (2013) ethnography of collaboration between a US-based university and a Kenyan NGO focused on HIV/AIDS education found the partnership sustaining and shifting post-colonial power relations.

Studies from the discourse tradition draw on case studies to capture participants' lived experiences of collaborating that highlight dynamics of discourse and language use such as participants' coping with the tensions of collaborating (e.g., Barbour \& James, 2015; Cooren, Brummans, \& Charrieras, 2008; Koschmann, 2013, 2016). For example, Maguire and Hardy (2005) conducted a case study of a Canadian HIV/AIDS multi-sector collaboration comprised of various NGOs and pharmaceutical companies. They found individuals using various strategies to manage tension between identifying with their home organization and identifying with the multi-sector collaboration (e.g., disidentification from home organization).

Of the three research traditions, the IOC discourse tradition goes the furthest in providing a discursive perspective on collaborative forms. This tradition draws on several ideas from the Montreal School's communication-as-constitutive-of-organization (CCO) perspective. The paper next summarizes several of the Montreal School's ideas and adapts them to this study.

\subsection{The Montreal School's CCO Perspective}

In a review of the organizational communication literature, Smith (1993) forwarded three root metaphors of the organization-communication relationship: communication conceived as taking place within an organization (the container metaphor), communication regarded as producing the organization and/or the organization producing communication (the production metaphor), and communication and organization as "variant expressions for the same reality" (the equivalence metaphor; J. R. Taylor, Cooren, Giroux, \& Robichaud, 1996 p. 28). Both the container and the production metaphors conceive of organizations as entities that can be separated from communication, and, in most instances, reify them and assume their primacy over communication. The equivalence metaphor, on the other hand, 
suggests mutual constitution and a communicational worldview whereby organizations can be thought of as emerging and existing in communication (Ashcraft, Kuhn, \& Cooren, 2009). In their review of the organizational discourse literature, Fairhurst and Putnam (2004) similarly found what they referred to as a grounded in action orientation where "the organization never assumes the form of an identifiable entity because it is anchored at the level of social practice and discursive forms" (p. 16).

The Montreal School's CCO perspective resonates with Smith's (1993) equivalence metaphor and Fairhurst and Putnam's (2004) grounded in action orientation (J. R. Taylor \& Van Every, 2000). The fundamental unit is neither a reified organization nor collective but discourse and social interaction. Entities (or actants) with variable ontologies such as humans, objects, and organizations participate in discourse and social interaction. Actants participate neither as humans nor non-humans but as hybrid associations between humans and non-humans (for example, the organization-as-actant can speak because of its hybrid associations with policy documents and spokespersons). Due to these associations, both human and non-human actants are endowed with agency, defined as the "ability to make a difference” (e.g., Brummans, Cooren, Robichaud, \& Taylor, 2014; Cooren, 2006; Fairhurst \& Cooren, 2009; J. R. Taylor, 1999).

The Montreal School's CCO perspective finds expression in the dialectic of conversation and text that animates social interaction (e.g., J. R. Taylor et al., 1996). Conversations refer to talk and interactions that take place in time and space. Talk has the capacity to express as well as produce reality (J. R. Taylor \& Cooren, 1997). Hence, conversation is regarded as the site for the creation of organizations. Social interaction is simultaneously animated by texts. Texts transcend time and space and have more enduring qualities than conversations. Texts, such as documents and logos, are the surfaces upon which the trans-local aspects of a social collective can be read.

Through hybrid associations, a trans-local text, such as an organization can act, speak, and be invoked in social interaction (e.g., J. R. Taylor \& Cooren, 1997). In specific, a social collective can speak through human (macroactors such as leaders and spokespersons) and non-human agents (Cooren et al., 2008; Fairhurst \& Cooren, 2009). Leaders and spokespersons endowed with authority by a collective can incarnate (or embody) the collective and, as such, animate, in social interaction, its trans-local qualities such as identity and image (see Cooren et al., 2008). One textual focus of the Montreal School has been the communicative constitution of a social collective's identity (e.g., Cooren et al., 2008; J. R. Taylor \& Cooren, 1997). For example, J. R. Taylor (1999) wrote "The text is the carrier of the organizational intention and identity, individuals' actions and interaction its instrument" (p. 48).

\subsubsection{A CCO Perspective on Non-profits}

The Montreal School's perspective has been adapted to non-profit organizations (NPOs; e.g., Dempsey, 2012). Koschmann (2012) called for emphases on the communicative constitution of NPOs and the NPO sector. He advocated specifically for the development of a Montreal School CCO perspective when he wrote, "we could begin articulating a communicative theory of the nonprofit sector or nonprofit organizations based on the Montreal School ideas of text-conversation dialectics" (p. 143-144).

A discursive foundation for collaborative forms in the NPO sector lies in the hybridity between such forms and the human and non-human agents that it appropriates and/or that speak on its behalf. Through such appropriations/incarnations, collaborative forms can participate in social interactions. They become agents that can express their identities, intentions, and objectives.

\subsection{Rationale and Research Questions}

Although health communication studies of HIV/AIDS have acknowledged the roles of HIV/AIDS NGOs (e.g., Muturi, 2008), we know less about how these organizations are collaborating in response to the epidemic in sub-Saharan Africa. Drawing on the NCF's focus on the collaborations of HIV/AIDS NGOs in sub-Saharan Africa, a discursive perspective on such collaborations, and Koschmann's (2012) call for a focus on the communicative constitution of the NGO sector, the study posed the following research questions of collaborative forms in Tanzania's HIV/AIDS NGO sector.

RQ1: Which collaborative forms are present in the discourse of macroactors (i.e., leaders/spokespersons) for local HIV/AIDS NGOs in Tanzania?

RQ2: What texts (i.e., identities) of the collaborative forms in Tanzania's HIV/AIDS NGO sector are being made present in the discourse of macroactors?

\section{Method}

\subsection{Context}

Tanzania is a nation of 51 million that has 1.5 million people living with HIV/AIDS ("Central Intelligence Agency," 2015; "United Nations Programme on HIV/AIDS," 2015). 


\subsection{Procedures}

The first author initiated this field study in Tanzania. ${ }^{2}$ Similar to previous research (e.g., Bastien, 2009), the study received authorization from Tanzania's Commission for Science and Technology and the Institutional Review Board of the authors' university.

The first author recruited macroactors for HIV/AIDS NGOs in Dar es Salaam, a city of 5 million that is the most populated in Tanzania ("Central Intelligence Agency," 2015). It has an adult HIV/AIDS prevalence rate of 7\% (31\% for female commercial sex workers, $22 \%$ for men who have sex with men, and $16 \%$ for intravenous drug users) ("Results from the 2011-12 Tanzania HIV/AIDS and Malaria Indicator Survey: HIV Fact Sheet by Region," 2015). Recruiting took place through site visits to NGOs, phone calls, SMS text messages, e-mails, and snowball sampling. Interested participants scheduled interviews to take place in NGO offices. The first author began the interviews with participants completing informed consent forms and a demographics questionnaire ${ }^{3}$. The first author conducted semi-structured interviews in English ${ }^{4}$ while audio-recording and taking notes. Upon completion, the first author compensated each participant $\$ 15$ in TZ shillings for their time ${ }^{5}$ and asked for their contacts of macroactors for Tanzanian HIV/AIDS NGOs. The first author collected NGO documents when available in English.

The first author completed 17 interviews in Tanzania over three months. While there, the first author was enrolled in a short course in Swahili and visited places such as Arusha, Bagamoyo, and Kigoma. To reach saturation, the first author later conducted 19 additional audio-recorded interviews through Skype from the US. The 36 total interviews averaged 52.69 minutes (ranging from 26.75 to 77.52). To enhance credibility, a professional transcriptionist of east African descent who comfortably understood participants' accents was employed (Lincoln \& Guba, 1985). Through several iterations, the transcripts were also improved for accuracy by a team of graduate students, resulting in approximately 500 single-spaced pages.

\subsection{Participants}

All 36 participants were native Tanzanians who represented 34 NGOs. Except for two participants who were interviewed from one NGO and another two from a different NGO, each participant represented one NGO. They held titles such as "Chief Executive Officer" and "Head of HIV Department." Fifteen were female and 21 were male. They averaged 40.47 years of age (ranging from 23 to 62). Eleven had Bachelor's degrees, 10 had the equivalent of a high school education, seven had Master's degrees, seven indicated "other," and one did not indicate an educational level. They averaged 7.83 years with their current NGO (ranging from 1 to 23).

HIV/AIDS NGOs. Participants' NGOs differed in several ways. On average, they had been in existence for 10.34 years (ranging from 1 to 25). Fourteen indicated their NGOs were community-based and 22 indicated their NGOs were national. The NGOs averaged 15.68 full-time employees (ranging from 0 to 200) and 38.09 volunteers (ranging from 0 to 275$)$.

\subsection{Data Analysis}

The study drew on a collaborative constant comparative method (CCCM), which harnesses the collaborative and independent efforts of a group of coders to generate themes ${ }^{6}$. The study's credibility (Lincoln \& Guba, 1985) was

\footnotetext{
${ }^{2}$ The authors' university had pre-existing linkages with people and organizations in Tanzania (e.g., study abroad opportunities for undergraduate students).

${ }^{3}$ The demographics questionnaire contained variables such as age, education, and gender.

${ }^{4}$ Sample questions included: "Please share with me a profile of your NGO," "Please describe the HIV/AIDS work of your NGO," "How do you define interorganizational collaboration," "Please share your NGO's experiences collaborating with organizations in Tanzania."

${ }^{5}$ The study recruited NGO leaders, most of whom maintain quite busy schedules. Because interviews were conducted during work hours, participants were offered payment to compensate them for their time. Furthermore, because participants were well-qualified, knowledgeable professionals and the $\$ 15$ compensation can be considered moderate, this amount is unlikely to affect the reliability of the data

${ }^{6}$ This study is based on communicational and co-constructive meta-theoretical perspectives. The communicational perspective is grounded on the notion that human and non-human agents can speak from distances. Trans-local texts such as organizational entities or social collectives can communicate and present themselves in situated contexts of discourse and social interaction through their hybrid associations with macroactors who have the authority to speak on behalf of organizations and social collectives. The co-constructive perspective draws on the idea that the presentification of a text is partly based on the subjectivity of those to whom the text is presenting itself. Since these
} 
further enhanced because one of the coders who was fluent in Swahili interpreted participants' uses of Swahili phrases. The CCCM involved identifying units, open coding, and axial coding (Corbin \& Strauss, 2015) ${ }^{7}$. Units are the most basic pieces of data (Miles, Huberman, \& Saldana, 2014). The study relied on units of meaning or semantic relationships (Spradley, 1979) because they can be specified in direct relevance to research questions, they are not limited to a standard size, and they encourage analysts to probe latent content (Hsieh \& Shannon, 2005). For RQ1, based on $\mathrm{X}$ as an explicit or implicit unit, the team searched the first five transcripts for "participant understands IOC as $\mathrm{X}$ " and "participant's experience reflects an understanding of IOC as X."

The CCCM also consists of open coding. This involves labeling units and constant comparison among units (Corbin \& Strauss, 2015). After open coding the first five interviews, the team developed a preliminary coding scheme (PCS) designed to assist the independent coding of team members by facilitating the recording of (a) coding decisions among an array of emergent themes and (b) coding decisions that did not fit with emergent themes.

The team collaboratively used the PCS to code five more interview transcripts. After coding decisions were collaboratively made, they were recorded on the PCS. The team observed the practice of coding a unit into different themes when deemed appropriate (Glaser, 1978).

After collaboratively coding ten interview transcripts, the team transitioned to independent coding where the remaining transcripts were divided among three coders. The PCS was stored as a shared electronic worksheet that allowed the three coders to asynchronously record their coding decisions. Coders agreed on conceptual saturation for RQ1 at the $26^{\text {th }}$ transcript (Corbin \& Strauss, 2015). To enhance confirmability of emergent themes, coders searched the remaining transcripts for further support of these themes before transitioning to axial coding.

Axial coding identifies broader relationships among themes (Corbin \& Strauss, 2015). The coders discussed different possible relationships among themes and labels for emergent categories. This process continued until a structure (of categories and sub-categories) emerged. Although two categories emerged, the study presents only the "HIV/AIDS NGO networks" category because it makes a stronger contribution to knowledge.

After axial coding for RQ1, the team turned to RQ2. Data to address RQ2 were constituent units of the "HIV/AIDS NGO networks" category from RQ1 and six interviews with macroactors for networks of PLWHA organizations ${ }^{8}$. Beginning with units of " $X$ as an identity marker of networks of PLWHA organizations," the team performed the CCCM on leader discourse on networks of PLWHA organizations.

\section{Findings}

\subsection{HIV/AIDS NGO Networks}

For RQ1, the study found the collaborative form of HIV/AIDS NGO networks. The following sections distinguish between HIV/AIDS service networks and PLWHA networks and further distinguish local PLWHA networks (within Tanzania) from regional (spanning neighboring countries) and global PLWHA networks.

Local NGO Networks. Local networks spanned geographical areas of Tanzania. Although macroactors for local networks mainly represented networks of PLWHA organizations, in some instances they represented and/or spoke of HIV/AIDS service networks.

Unlike networks of PLWHA organizations, HIV/AIDS service networks were not primarily composed of PLWHA. Instead they consisted of organizations that provided various HIV/AIDS-related services. Yet both types of networks were similar in their advocacy-related function. The following participant offered an example.

We formed a network of organizations that were working with HIV/AIDS. We called it Tanzania HIV Collaborative ${ }^{9}$ We were the pioneers, we developed the concept, we facilitated the first meetings, we did constitution, we registered, and we were the first chair, first secretariat, hosting them here. We put pressure on the government on what we wanted

audiences are drawing on subjective experience and knowledge to identify, read, and understand texts, they are, in a sense, active participants in constructing the text. Texts can thus be considered co-constructions among analysts, audiences, and authors (Cooren et al., 2008; J. R. Taylor, 1999; J. R. Taylor \& Cooren, 1997).

${ }^{7}$ By excluding the last step of grounded theory (selective coding; Glaser \& Strauss, 1967), the steps of the CCCM can be informed by, or draw guidance from, a pre-existing theory and/or a set of sensitizing concepts.

${ }^{8}$ Although the sample contained six macroactors for networks of PLWHA organizations, approximately 18 of the study's participants spoke about HIV/AIDS NGO networks, consisting of either PLWHA organizations or HIV/AIDS service organizations.

${ }^{9}$ This is a pseudonym for the network. 
to be done with HIV/AIDS (male executive director).

This participant described the formation of a network of organizations (i.e., initial meetings, constitution, registration) that was never identified as a PLWHA network. This network, initially led by his NGO, sought to pressure the government of Tanzania with its HIV/AIDS-related demands.

In addition to HIV/AIDS service networks, participants spoke mostly of networks of PLWHA organizations. In most cases, the network's name disclosed the HIV-positive status of its members. Macroactors saw these networks as beneficial for greater involvement of PLWHA in decision-making forums, for mitigating HIV/AIDS stigma and discrimination in Tanzania, and for obtaining funds for HIV/AIDS programs. The following macroactor spoke of these networks as mechanisms for involving PLWHA in decision- and policy-making forums:

For greater involvement of PLWHA, you must have a mechanism that can link with the decision makers at the national level. Without that, you can't sit together. So, it helps us communicate, advocate, and to sit together with the decision makers and policy makers (male executive chairperson).

In addition to networks in Tanzania, macroactors also spoke of regional and global PLWHA networks.

Regional and Global PLWHA Networks. The following macroactor spoke of his NGO as one of the founding members of a regional east-African network of PLWHA organizations.

I was the one who collaborated with Kenya, Uganda in the early 1990s to have a big network implemented in the HIV/AIDS area. We started as three countries: Kenya, Uganda, and Tanzania. After six years, I was a board member representing PLWHA organizations in that network. East African AIDS Network. After that, we expanded to 13 countries including Rwanda, Burundi, and Sudan. We expanded and now we are a big network in the region (male executive director).

This regional network, initially consisting of PLWHA organizations in the east-African countries of Kenya, Tanzania, and Uganda, later expanded to include 13 countries in east Africa. Another macroactor for a national network of PLWHA organizations went beyond the east-African network to identifying other regional networks of PLWHA ${ }^{10}$ :

I: Ok. Thank you. Now is it easier to collaborate globally by being a national network?

P: No, you can't collaborate globally like that. That's why we have a regional network that's based in Kenya that comprises national networks of 15 countries of the eastern Africa region. Yes. Different countries, 18 countries of the eastern Africa region.

I: Ok.

P: From that, also there is a regional network in South African countries. And there is the regional network for Indian Ocean countries (male executive chairperson).

In this macroactor's discourse, he identified the regional-level PLWHA networks of east Africa, south Africa, and Indian-ocean countries. In addition to regional networks, he also spoke of global PLWHA networks, "So from there, from the African continent we are linking to the global network of people living with HIV/AIDS based in Netherlands" (male executive chairperson). Similarly, another macroactor for a national network broached the global network, "We also collaborate with other international organizations that are outside the country. For instance, now, the global network of PLWHA. They are based in the Netherlands but they have their regional office in South Africa" (male chief executive officer). Although macroactors spoke of collaboration among the PLWHA networks within and across scales, there was no evidence to suggest these networks were organized in parent-subsidiary relationships. Rather, macroactors mostly spoke of the networks as independent of each other. For RQ1, participants spoke about HIV/AIDS NGO networks. They reported on both HIV/AIDS service networks and PLWHA networks. Further, they described the PLWHA networks as local, regional, or global in scale.

\subsection{The Identities of Networks of PLWHA Organizations}

RQ2, which queried the identities of PLWHA networks, resulted in three findings: networks as single entities that unify PLWHA organizations in/across administrative divisions of Tanzania, networks as structures for reaching grassroots PLWHA and facilitating their participation in decision making at various scales (e.g., national), and networks as vehicles for various social impacts.

\subsubsection{Single Entities that Unify PLWHA Organizations In/Across Administrative Divisions}

The networks presented themselves as single identities that were similar to and different from networks of PLWHA organizations. They were similar as single entities constituted by numerous PLWHA organizations and as unifying

10"I" is a transcript notation that refers to "interviewer." "P" refers to "participant." 
mechanisms for these organizations. For example, a male chief executive officer spoke of his network as being constituted by PLWHA, "They are people living with HIV/AIDS. But since they are PLWHA, they are part of the network." The following interview with a male executive chairperson further revealed his network's constitution by PLWHA organizations:

I: Ok. I see. So, your organization is really composed of many different organizations.

P: Yes. Many different organizations, non-governmental organizations.

I: Are these HIV/AIDS non-governmental organizations?

P: These are organizations of people living with HIV/AIDS.

The networks were also similar as entities that unify PLWHA organizations. An example came from a male general secretary who said, "We come together, our voices become one and we develop strategies. Because when you work as a team or as a network, you find that most of the problems facing people with HIV/AIDS are the same." Several macroactors also pointed to the nature of the network organization's registration, which recognized it as a single entity. An example came from a male project coordinator who described a network as follows, "But it's like a network of organizations in the region. Within that network, there are several organizations working together. It is registered as an organization, a network of organizations."

In addition to similarities, the networks also presented themselves as single entities that differ from one another in their members' identities (e.g., age, gender) and in their geographical spread. For example, a male executive chairperson gave the following examples of the identity composition of PLWHA networks, "youth networks, people with disability living with HIV/AIDS, HIV/AIDS widows networks." A female executive chairperson described the identity of her network members as follows, "we have got women groups and other district organizations of women living with HIV."

The networks also differed in their geographical jurisdiction. Some operated within a district (or community). Dar es Salaam, for example, is divided into districts such as Ilala, Kinondoni, and Temeke. A male general secretary described his network as "Based on a district. The number of members from this organization are around 50 organizations." In contrast, others operated across districts. For example, the following macroactor represented such a network, "We are a network of [PLWHA]. It is a coalition of three district networks. One is for Kinondoni district, the other one is Temeke and one is Ilala" (male program coordinator). In contrast to district-based networks, macroactors, such as the following one, spoke on behalf of national-level networks, "This is a national network of people living with HIV. By saying national I mean our coverage and scope covers the whole country" (male chief executive officer). Macroactors presented networks as single entities that were similar and different. They were similar in their constitution by several PLWHA organizations and as unifying mechanisms and they differed in their members' identities and in their geographical jurisdiction.

\subsubsection{Structures for Reaching and Involving Grassroots PLWHA}

In addition to presenting an identity as single entities that had similarities and differences, the networks also presented an identity as structures for reaching the grassroots and facilitating the participation of PLWHA. On one hand, macroactors presented their networks as embedding several grassroots networks. For example, a male executive chairperson of a national network said, "our organization is a national network with 76 district networks around the country. We have 76 networks at the district level." By characterizing the networks as "district networks," the macroactor is emphasizing the national network's roots in local communities. On the other hand, macroactors presented networks as embedding several grassroots organizations. Macroactors repeatedly used terms such as "small" or "community" to characterize the grassroots orientation of constituent organizations. For example, the male program coordinator for a three-district network presented one network as follows, "Kinondoni alone has 42 small NGOs which are members of this network." The macroactor went on describe his three-district network, "In total, members of the three networks will be about $60-80$ community-based organizations."

In addition to reaching the grassroots, macroactors presented the networks as enhancing the participation of PLWHA at the grassroots and at scales beyond the grassroots. A male program coordinator for a three-district network spoke of how his network improved the involvement of PLWHA in a community, "with any intervention being done in the municipal [or district], we are consulted and we give our consent or we participate. So, in everything relating to HIV done by any council or government, we participate. In the past, that was a dream." A male executive chairperson for a national network also spoke of enhancing PLWHA participation, "When you see the other side of greater involvement of people living with HIV/AIDS, you must have a mechanism that can link with the decision maker at the national level." This macroactor then went on to indicate the various scales at which his national network enhanced the participation of PLWHA, "At all levels from the district level up to the national." 


\subsubsection{Vehicles for Social Impacts}

In addition to the network identity as structures for reaching the grassroots and facilitating the involvement of PLWHA, macroactors presented a network identity as pursuing several objectives. They spoke of networks as vehicles for advocacy for PLWHA, as vehicles for the care and treatment of PLWHA, and as vehicles for educating community members. Several spoke of their advocacy mission. For example, a male coordinator of research said, "Networks can join together so they can raise up their voices so that they can become strong and maybe to be heard, their voices to be heard with those people in power." A male chief executive officer spoke of the historical conditions out of which his network emerged, "There was no strong coordinating body that could bring them [PLWHA] together, or to create a forum for PLWHA to voice their rights, to voice their needs, and to influence policies, programs, and services." He then described his network's mission, "[This network] was formed to be a national forum that can create a space and raise a voice of PLWHA." Macroactors also gave examples of their advocacy work. For example, a male general secretary for a district network spoke of intervening at a school where HIV-positive children were being identified with red ribbons:

We went to that school and talked to the teachers. We told them that this is not fair and this was a form of discrimination. This is a stigma in our country and we don't want this. This is illegal. So, we managed to solve that from there and they stopped it.

Similarly, a male chief executive officer also described his national network's intervention against the discrimination of HIV-positive children in schools. His description, though, pointed to his network's focus on changing discriminatory policies through collective action.

In the past, we actually wanted to influence some policies especially the policy that was discriminating school children who were living with HIV/AIDS. Because they were being labeled. We intervened and had some supporters from other organizations. The government also offered advice on those issues. If we were just alone, we would not have gone very far.

In another example, a male executive chairperson of a national network spoke of his network's confrontation with a pharmaceutical corporation based in Kenya, "We have been advocating in Kenya to reduce the price of the drugs. In the end, we find that we win that and the cost of the drug was dropped and now people are issuing the drugs in our country."

In addition to advocacy, macroactors presented networks as vehicles for the care and treatment of PLWHA. For example, a male executive chairperson of a national network said, "We are caring for people who are bed-ridden. That means home-based care. And in treatment, we are providing training for treatment adherence and treatment preparedness." Several described missions focused on vulnerable populations affected by HIV/AIDS. For example, an executive director of a national network spoke of a focus on rural populations, "We are using our organization to help people who are living in villages outside of Dar es Salaam. We call remote areas." This macroactor later described his network's operations to link organizations based outside Tanzania with rural PLWHA, "They collaborate with us to know more about HIV positive people living in the village. We take them to the communities to look at them and where the people live."

In addition to care and treatment of PLWHA, macroactors also described the network objective of educating community members. A male executive director of a national network described some of his network's activities as follows, "visiting of home patients to educate the patients with the family. There is education for community, sensitization of the community to know what HIV/AIDS is." Similarly, a male general secretary contributed, "We used to talk with the colleges, teachers, just to share experiences. We just educate them and share our knowledge." For RQ2, the study found PLWHA networks as single entities that unify PLWHA organizations within and across administrative divisions of Tanzania, as structures for reaching grassroots PLWHA and enhancing their participation at various scales, and as vehicles for a variety of social impacts (e.g., advocacy for PLWHA).

\section{Discussion}

For RQ1, the study finds macroactors speaking for and about HIV/AIDS NGO networks. Although they spoke for HIV/AIDS service networks, they dominantly spoke for networks of PLWHA organizations. Moreover, they characterized these PLWHA networks as operating at local, regional, and global scales. For RQ2, the study finds PLWHA networks presenting several identities (i.e., as single entities that unify PLWHA organizations; as structures for reaching grassroots PLWHA and facilitating their participation at various scales; and as vehicles for the advocacy and care/treatment of PLWHA and the education of community members).

Some of the study's findings are consistent with those of previous research. First, the study finds HIV/AIDS NGOs participating in networks. Diop (2000), in his treatise on Senegal's and Uganda's successful confrontations with the HIV/AIDS epidemic, identified the presence of networks of organizations. Whereas Diop offered little in the way of 
detail about these networks, this study's findings begin to help us understand the constitution, functions, types, and variations of these networks. Second, this study's participants spoke of HIV/AIDS service networks. Previous research in the global North has also focused on these networks (e.g., Khosla et al., 2016; Kwait et al., 2001). Yet, this study's participants introduced an advocacy function for such networks that is not usually emphasized in the literature. Third, the study finds an identity of PLWHA networks grounded in facilitating the participation of grassroots PLWHA in decision-making forums at various scales. Desouza and Dutta (2008), in their examination of messages exchanged in the e-forum of an Indian HIV/AIDS NGO, also found messages (a) encouraging members of a PLWHA organization to participate in decision making on HIV/AIDS programs and policies and (b) inviting NGOs to participate in the development of UNAIDS HIV programs. Whereas the ties between organizations in the e-forum were "loose," this study finds the NGO members of PLWHA networks involved in "close ties," reflected in their registrations as single entities. Fourth, the study finds an identity of the PLWHA networks as vehicles for the advocacy of PLWHA. Previous research has also recognized the advocacy mission for PLWHA by NGOs (e.g., DeJong \& Mortagy, 2013; Maguire \& Hardy, 2005). Yet, this study departs from previous ones in that advocacy for PLWHA is largely carried out through networks of organizations.

The study makes several contributions to the health communication and collaboration literatures. First, the finding of networks of PLWHA organizations contributes to the literature. Although Garcia and Parker (2011) also found nation-wide Afro-Brazilian religious networks that combatted HIV/AIDS by simultaneously being involved in local grassroots initiatives and national-level policy-making processes, the study's finding of networks composed exclusively of PLWHA organizations is novel ${ }^{11}$. This finding can be distinguished from Hardy and colleagues' studies of the Canadian Treatment Advocacy Council (CTAC) (e.g., Hardy et al., 2006) in that CTAC was a multi-sectoral collaboration. This study finds PLWHA networks composed exclusively of NGOs. Second, the study contributes a NPO sectoral-level view of PLWHA networks (Koschmann, 2012). Through such a view, we gain several insights into these networks such as their variation in scale from local to global, differences in their members' identities, and differences in their geographical jurisdiction and spread. Third, the study contributes a Montreal School CCO perspective that highlights network texts (i.e., identities) which, through hybrid associations between human and non-humans, were made present in the discourse of macroactors. Fourth, the finding of regional-level PLWHA networks also contributes to the literature. Several macroactors spoke of regional networks of PLWHA. Although a regional focus is emphasized by the NCF (Airhihenbuwa et al., 2000), few studies have focused on HIV/AIDS-related regional networks (Cooper \& Shumate, 2012; Murray et al., 2011).

The study's findings also contribute to the NCF's ecological context of government and policy. This context is based on the assumption that the effective response to epidemics in the global South involves governments setting the stage for HIV organizations to operate and collaborate (Airhihenbuwa et al., 2000). In a sense, this assumption, a top-down one, represents one way of responding. The finding of PLWHA networks that enhance participation in decision-making forums, suggests another viable response is based neither on a top-down nor bottom-up model, but on an inclusive or democratic one. Such an inclusive approach can go beyond the NGOs to multi-sectoral networks that integrate governmental, global North, and/or pharmaceutical actors. To the degree that actors can collaborate as equals, this may be a more effective and comprehensive approach to collaboratively responding to epidemics in the global South.

\subsection{Limitations and Future Research}

Although the study provides some insight into PLWHA networks in Tanzania, we can further our knowledge of regional-level and global-level PLWHA networks, particularly from a Montreal School CCO perspective (Cooren et al., 2008). For example, although the study focused on network identity as a trans-local text of PLWHA networks in Tanzania, future research can focus on the trans-local network identities of regional and/or global PLWHA networks. Furthermore, based on the notion that network formations are constituted in a dialectic of text and conversation, future research can examine how conversations between and among PLWHA network members co-construct, sustain, and

\footnotetext{
${ }^{11}$ Several researchers have recognized the different theories of HIV/AIDS prevention (Airhihenbuwa \& Obregon, 2000; Parkhurst \& Lush, 2004). Parkhurst and Lush (2004), for example, described these theories as focusing either on individual factors (e.g., Health Belief Model), social factors, or structural and environmental factors (p. 1914). The study's findings of the identities of PLWHA networks suggest the networks attended primarily to social factors and structural and environmental factors. On one hand, the finding of networks as entities that unify PLWHA organizations in/across administrative divisions of Tanzania and as embedding structures for reaching grassroots PLWHA and enhancing their participation in decision-making forums at various scales point to a structural approach to HIV/AIDS, one that emphasizes concerns such as democratic governance, policies/laws, and access to/availability of resources. On the other hand, the PLWHA networks' identities as vehicles for social impacts points to a social approach to HIV prevention, one that priorities a community-level and caring response to HIV.
} 
transform network texts. In such an investigation, one may explore the various tensions that network members experience and manage as they construct and (re)construct network identities.

Future research of PLWHA networks can also draw guidance from the culture-centered approach to health communication (Dutta, 2008). This perspective focuses partly on how marginalized actors in post-colonial contexts exercise health-related agency and engage in participatory processes amid particular cultural and structural configurations (e.g., Olufowote, 2017). Future research may, for example, focus on how regional and global PLWHA networks engage in processes of dialogue and participatory decision making both with network members and more powerful decision makers and the different forms of agency, activism, and resistance they exercise.

\subsection{Conclusion}

The study drew on the Montreal School perspective, a discursive perspective on NPOs and the NPO sector, to develop the discursive foundations of HIV/AIDS NGO collaborations in sub-Saharan Africa. For RQ1, the study finds the collaborative form of HIV/AIDS NGO networks (i.e., HIV/AIDS service networks and networks of PLWHA organizations). Participants described the networks of PLWHA organizations as operating at local, regional, or global scales. For RQ2, the study finds the PLWHA networks presenting several network identities in the discourse of their macroactors: single entities that unify PLWHA organizations within and across administrative divisions of Tanzania, structures that reach grassroots-level PLWHA and facilitate their involvement in decision-making forums at various scales, and vehicles for a variety of social impacts (e.g., advocacy for PLWHA).

\section{References}

Airhihenbuwa, C. O., Makinwa, B., \& Obregon, R. (2000). Toward a new communications framework for HIV/ AIDS. Journal of Health Communication, 5, 101-111. https://doi.org/10.1080/10810730050019582

Airhihenbuwa, C. O., \& Obregon, R. (2000). A critical assessment of theories/models used in health communication for HIV/ AIDS. Journal of Health Communication, 5, 5-15. https://doi.org/10.1080/10810730050019528

Ashcraft, K. L., Kuhn, T. R., \& Cooren, F. (2009). Constitutional amendments: Materializing organizational communication. The Academy of Management Annals, 3, 1-64. https://doi.org/10.1080/19416520903047186

Atouba, Y., \& Shumate, M. (2010). Interorganizational networking patterns among development organizations. Journal of Communication, 60, 293-317. https://doi.org/10.1111/j.1460-2466.2010.01483.x

Barbour, J. B., \& James, E. P. (2015). Collaboration for compliance: Identity tensions in the interorganizational and interdisciplinary regulation of a toxic waste storage facility. Journal of Applied Communication Research, 43, 363-384. https://doi.org/10.1080/00909882.2015.1083601

Bastien, S. (2009). Reflecting and shaping the discourse: The role of music in AIDS communication in Tanzania. Social Science \& Medicine, 68, 1357-1360. https://doi.org/10.1016/j.socscimed.2009.01.030

Basu, A., \& Dutta, M. J. (2009). Sex workers and HIV/AIDS: Analyzing participatory culture-centered health communication strategies. Human Communication Research, 35, 86-114. https://doi.org/10.1111/j.1468-2958.2008.01339.x

Bekalu, M. A., \& Eggermont, S. (2014). The role of communication inequality in mediating the impacts of socioecological and socioeconomic disparities on HIV/AIDS knowledge and risk perception. International Journal for Equity in Health, 13, 1-11. https://doi.org/10.1186/1475-9276-13-16

Brummans, B. H. J. M., Cooren, F., Robichaud, D., \& Taylor, J. R. (2014). Approaches to the communicative constitution of organizations. In L. L. Putnam \& D. K. Mumby (Eds.), The SAGE handbook of organizational communication: Advances in theory, research, and methods (3rd ed., pp. 173-194). Thousand Oaks, CA: SAGE.

Central Intelligence Agency. (2015). The world factbook: Tanzania. Retrieved from https://www.cia.gov/library/publications/the-world-factbook/geos/tz.html

Contu, A., \& Girei, E. (2014). NGOs management and the value of 'partnerships' for equality in international development: What's in a name? Human Relations, 67, 205-232. https://doi.org/10.1177/0018726713489999

Cooper, K. R., \& Shumate, M. (2012). Interorganizational collaboration explored through the bona fide network perspective. Management Communication Quarterly, 26, 623-654. https://doi.org/10.1177/0893318912462014

Cooren, F. (2006). The organizational world as a plenum of agencies. In F. Cooren, J. R. Taylor, \& E. J. Van Every (Eds.), Communication as organizing: Empirical and theoretical explorations in the dynamic of text and conversation. Mahwah, NJ: Lawrence Erlbaum. 
Cooren, F., Brummans, B. H. J. M., \& Charrieras, D. (2008). The coproduction of organizational presence: A study of Medecins Sans Frontieres in action. Human Relations, 61, 1339-1370. https://doi.org/10.1177/0018726708095707

Corbin, J., \& Strauss, A. (2015). Basics of qualitative research: Techniques and procedures for developing grounded theory (4th ed.). Thousand Oaks, CA: Sage.

Craig, R. T. (1999). Communication theory as a field. Communication Theory, 9, 119-160. https://doi.org/10.1111/j.1468-2885.1999.tb00355.x

Dako-Gyeke, P. (2013). "Safe sex talk": Negotiating safe sex practices in heterosexual relationships. Mediterranean Journal of Social Science, 4, 309-318. https://doi.org/10.5901/mjss.2013.v4n2p309

Dasgupta, S. (2013). Poverty as a contextual factor affecting sexual health behavior among female sex workers in India. Qualitative Health Research, 23, 825-833. https://doi.org/10.1177/1049732313483925

de Souza, R. (2009). Creating "communicative spaces": A case of NGO community organizing for HIV/ AIDS prevention. Health Communication, 24, 692-702. https://doi.org/10.1080/10410230903264006

Dearing, J. W. (2003). The state of the art and the state of the science of community organizing. In T. Thompson, A. Dorsey, K. Miller, \& R. Parrott (Eds.), Handbook of health communication (pp. 207-220). Mahwah, NJ: Lawrence Erlbaum Associates.

DeJong, J., \& Mortagy, I. (2013). The struggle for recognition by people living with HIV/AIDS in Sudan. Qualitative Health Research, 23, 782-794. https://doi.org/10.1177/1049732313482397

Dempsey, S. E. (2010). Critiquing community engagement. Management Communication Quarterly, 24, 359-390. https://doi.org/10.1177/0893318909352247

Dempsey, S. E. (2012). Nonprofits as political actors. Management Communication Quarterly, 26, 147-151. https://doi.org/10.1177/0893318911424375

Desouza, R., \& Dutta, M. J. (2008). Global and local networking for HIV/AIDS prevention: The case of the Saathii E-forum. Journal of Health Communication, 13, 326-344. https://doi.org/10.1080/10810730802063363

Diop, W. (2000). From government policy to community-based communication strategies in Africa: Lessons from Senegal and Uganda. Journal of Health Communication, 5, 113-117. https://doi.org/10.1080/10810730508956572

Dutta, M. J. (2008). Communicating heath: A culture-centered aproach. Malden, MA: Polity Press.

Fairhurst, G. T., \& Cooren, F. (2009). Leadership as the hybrid production of presence(s). Leadership, 5, 469-490. https://doi.org/10.1177/1742715009343033

Fairhurst, G. T., \& Putnam, L. L. (2004). Organizations as discursive constructions. Communication Theory, 14, 5-26. https://doi.org/10.1111/j.1468-2885.2004.tb00301.x

Garcia, J., \& Parker, R. G. (2011). Resource mobilization for health advocacy: Afro-Brazilian religious organizations and HIV prevention and control. Social Science \& Medicine, 72, 1930-1938. doi:10.1016/j_socscimed.2010.05.010

Glaser, B. G. (1978). Theoretical sensitivity: Advances in the methodology of grounded theory. Mill Valley, CA: Sociology Press.

Glaser, B. G., \& Strauss, A. L. (1967). The discovery of grounded theory. Chicago: Aldine.

Guo, C., \& Acar, M. (2005). Understanding collaboration among nonprofit organizations: Combining resource dependency, institutional, and network perspectives. Nonprofit and Voluntary Sector Quarterly, 34, 340-361. https://doi.org/10.1177/0899764005275411

Hardy, C., Lawrence, T. B., \& Phillips, N. (2006). Swimming with sharks: Creating strategic change through multi-sector collaboration. International Journal of Strategic Change Management, 1, 96-112. https://doi.org/10.1504/IJSCM.2006.011105

Hsieh, H., \& Shannon, S. E. (2005). Three approaches to qualitative content analysis. Qualitative Health Research, 15, 1277-1288. https://doi.org/10.1177/1049732305276687

Jennings, M. (2015). The precariousness of the franchise state: Voluntary sector health services and international NGOs in Tanzania, 1960s -mid-1980s. Social Science \& Medicine, 141, 1-8. https://doi.org/10.1016/j.socscimed.2015.07.018

Khosla, N., Marsteller, J. A., Hsu, Y. J., \& Elliott, D. L. (2016). Analysing collaboration among HIV agencies through combining network theory and relational coordination. Social Science \& Medicine, 150, 85-94. https://doi.org/10.1016/j.socscimed.2015.12.006 
Kiley, E. E., \& Hovorka, A. (2006). Civil society organisations and the national HIV/AIDS response in Botswana. African Journal of AIDS Research, 5, 162-178. https://doi.org/10.2989/16085900609490377

Kiwanuka-Tondo, J., Albada, K. F., Waters, R. D., Jameson, J. K., \& Hamilton, M. (2011). AIDS communication campaigns in Uganda. Journal of Communication Management, 17, 5-23. https://doi.org/10.1108/13632541311300124

Koschmann, M. A. (2012). Developing a communicative theory of the nonprofit. Management Communication Quarterly, 26, 139-146. https://doi.org/10.1177/0893318911423640

Koschmann, M. A. (2013). The communicative constitution of collective identity in interorganizational collaboration. Management Communication Quarterly, 27, 61-89. https://doi.org/10.1177/0893318912449314

Koschmann, M. A. (2016). Economic sectors as discursive resources for civil society collaboration. Communication Quarterly, Advance online publication. https://doi.org/10.1080/01463373.2015.1103295

Kwait, J., Valente, T. W., \& Celentano, D. D. (2001). Interorganizational relationships among HIV/AIDS service organizations in Baltimore: A network analysis. Journal of Urban Health: Bulletin of the New York Academy of Medicine, 78, 468-487. https://doi.org/10.1093/jurban/78.3.468

Lees, S., Kielmann, K., Cataldo, F., \& Gitau-Mburu, D. (2012). Understanding the linkages between informal and formal care for people living with HIV in sub-Saharan Africa. Global Public Health, 7, 1109-1119. https://doi.org/10.1080/17441692.2012.733403

Lewis, L., Isbell, M. G., \& Koschmann, M. (2010). Collaborative tensions: Practitioners' experiences of interorganizational relationships. Communication Monographs, 77, 460-479. https://doi.org/10.1080/03637751.2010.523605

Lincoln, Y. S., \& Guba, E. G. (1985). Naturalistic inquiry. Newbury Park, CA: Sage.

Maguire, S., \& Hardy, C. (2005). Identity and collaborative strategy in the Canadian HIV/AIDS treatment domain. Strategic Organization, 3, 11-45. https://doi.org/10.1177/1476127005050112

Miles, M. B., Huberman, A. M., \& Saldana, J. (2014). Qualitative data analysis: A methods sourcebook (3rd ed.). Thousand Oaks, CA: Sage.

Murphy, A. G. (2013). Discursive frictions: Power, identity, and culture in an international working partnership. Journal of International and Intercultural Communication, 6, 1-20. https://doi.org/10.1080/17513057.2012.740683

Murray, L. R., Garcia, J., Munoz-Laboy, M., \& Parker, R. G. (2011). Strange bedfellows: The Catholic Church and Brazilian National AIDS Program in the response to HIV/AIDS in Brazil. Social Science \& Medicine, 72, 945-952. https://doi.org/10.1016/j.socscimed.2011.01.004

Muturi, N. (2008). Faith-based initiatives in response to HIV/ AIDS in Jamaica. International Journal of Communication, 2, 108-131.

Muturi, N. (2011). Religiosity, HIV risk, communication, and HIV-related interventions within faith communities in Jamaica. In A. N. Miller \& D. L. Rubin (Eds.), Health communication and faith communities (pp. 163-186). New York, NY: Hampton Press.

Norander, S., \& Harter, L. M. (2012). Reflexivity in practice: Challenges and potentials of transnational organizing. Management Communication Quarterly, 26, 74-105. https://doi.org/10.1177/0893318911415607

Olufowote, J. O. (2017). An institutional field of people living with HIV/AIDS organizations in Tanzania: Agency, culture, structure, and dialogue. Frontiers in Communication [Health Communication section], 2. https://doi.org/10.3389/fcomm.2017.00001

Parkhurst, J. O., \& Lush, L. (2004). The political environment of HIV: lessons from a comparison of Uganda and South Africa. Social Science \& Medicine, 59, 1913-1924. https://doi.org/10.1016/j.socscimed.2004.02.026

Results from the 2011-12 Tanzania HIV/AIDS and Malaria Indicator Survey: HIV Fact Sheet by Region. (2015). Retrieved from http://www.egov.go.tz/egov_uploads/documents/HIVFactsheetbyRegion_sw.pdf

Shumate, M., \& Dewitt, L. (2008). The North/ South divide in NGO hyperlink networks. Journal of Computer-Mediated Communication, 13, 405-428. https://doi.org/10.1111/j.1083-6101.2008.00402.x

Shumate, M., Fulk, J., \& Monge, P. (2005). Predictors of the international HIV/ AIDS INGO network over time. Human Communication Research, 31, 482-510. 
Smith, R. C. (1993). Images of organizational communication: Root-metaphors of the organization-communication relationship. Paper presented at the International Communication Association conference, Washington, DC.

Spradley, J. P. (1979). The ethnographic interview. New York: Holt, Rinehart and Winston.

Svenkerud, P. J., \& Singhal, A. (1998). Enhancing the effectiveness of HIV/AIDS prevention programs targeted to unique population groups in Thailand: Lessons learned from applying concepts of diffusion of innovation and social marketing. Journal of Health Communication, 3, 193-216. https://doi.org/10.1080/108107398127337

Takahashi, L. M., \& Smutny, G. (2001). Collaboration among small, community-based organizations. Journal of Planning Education and Research, 21, 141-153. https://doi.org/10.1177/0739456x0102100203

Taylor, J. R. (1999). What is "Organizational Communication"? communication as a dialogic of text and conversation. The Communication Review, 31, 21-63. https://doi.org/10.1080/10714429909368573

Taylor, J. R., \& Cooren, F. (1997). What makes communication 'organizational'? Journal of Pragmatics, 27, $409-438$. https://doi.org/10.1016/S0378-2166(96)00044-6

Taylor, J. R., Cooren, F., Giroux, N., \& Robichaud, D. (1996). The communicational basis of the organization: Between the conversation and the text. Communication Theory, 6, 1-39. https://doi.org/10.1111/j.1468-2885.1996.tb00118.x

Taylor, J. R., \& Van Every, E. J. (2000). The emergent organization: Communication as its site and surface. Mahwah, NJ: Lawrence Erlbaum.

Taylor, M., \& Doerfel, M. L. (2003). Building interorganizational relationships that build nations. Human Communication Research, 29, 153-181. https://doi.org/10.1111/j.1468-2958.2003.tb00835.x

United Nations Programme on HIV/AIDS. (2015). HIV estimates with uncertainty bounds 1990-2014. Retrieved from http://www.unaids.org/en/resources/documents/2015/HIV_estimates_with_uncertainty_bounds_1990-2014

Uwah, C. (2014). The role of culture in effective HIV/AIDS communication by theatre in South Africa. Journal of Social Aspects of HIV/AIDS, 10, 140-149.

Werber, L., Derose, K. P., Dominguez, B. X., \& Mata, M. A. (2012). Religious congregations' collaborations: With whom do they work and what resources do they share in addressing HIV and other health issues? Health Education \& Behavior, 49, 777-788. https://doi.org/10.1177/1090198111434595

Zoller, H. M. (2010). What are health organizations? Public health and organizational communication. Management Communication Quarterly, 24, 482-490. https://doi.org/10.1177/0893318910370273

\section{Copyrights}

Copyright for this article is retained by the author(s), with first publication rights granted to the journal.

This is an open-access article distributed under the terms and conditions of the Creative Commons Attribution license which permits unrestricted use, distribution, and reproduction in any medium, provided the original work is properly cited. 